\title{
Invasive pulmonary aspergillosis in COVID-19. A case series at Gregorio Maranon University General Hospital
}

\author{
Aspergilosis pulmonar invasiva en COVID-19. Serie de casos en \\ el Hospital General Universitario Gregorio Marañón
}

\author{
Alba Burgos Santamaría ${ }^{1, *}$, María Lema T. ${ }^{1}$, Ana Gloria Pizarro C. ${ }^{1}$ \\ 1 Hospital General Universitario Gregorio Marañón. Madrid, España.
}

Fuente de financiación: No existe fuente de financiación.

Conflictos de intereses: Los autores del artículo no poseen conflictos de intereses que influyeran en el desarrollo del estudio.

Fecha de recepción: 23 de enero de 2021 / Fecha de aceptación: 12 de febrero de 2021

\begin{abstract}
Purpose: Patients with acute respiratory distress syndrome (ARDS) due to viral infection admitted at ICU are at risk for secondary complications like invasive pulmonary aspergillosis. Our study evaluates severe ARDS due to COVID-19 associated invasive pulmonary aspergillosis at a single center in Madrid, Spain. Materials and Methods: A retrospective chart review of patients with COVID-19 associated ARDS admitted to two of the five ICUs that were available at the Gregorio Maranon University General Hospital, Madrid, Spain. Results: COVID-19 associated invasive pulmonary aspergillosis was found in 4 of 79 critically ill patients with severe ARDS. Conclusion: Patients with ARDS triggered by COVID-19 seem to be at risk of developing invasive pulmonary aspergillosis, being necessary the early diagnosis and treatment in order to improve their prognosis.
\end{abstract}

Key words: COVID-19, aspergillus, invasive pulmonary aspergillosis, acute respiratory distress syndrome.

\section{RESUMEN}

Objetivo: Los pacientes con síndrome de distrés respiratorio agudo (SDRA) secundario a infección viral que requieren ingreso en UCI presentan mayor riesgo de complicaciones secundarias como aspergilosis pulmonar invasiva. En el presente estudio evaluamos aquellos pacientes con COVID-19 y SDRA severo que desarrollaron aspergilosis pulmonar invasiva en un único centro en Madrid, España. Material y Métodos: Se llevó a cabo un estudio retrospectivo, incluyendo aquellos pacientes con COVID-19 y SDRA ingresados en dos de las cinco UCI disponibles en el Hospital General Universitario Gregorio Marañón, Madrid, España. Resultados: La aspergilosis pulmonar invasiva asociada a COVID-19 se encontró en 4 de los 79 pacientes con SDRA severo. Conclusiones: Los pacientes con SDRA secundario a COVID-19 podrían presentar mayor riesgo de desarrollar aspergilosis pulmonar invasiva, siendo necesario un diagnóstico y tratamiento precoz con el fin de mejorar su pronóstico.

Palabras clave: COVID-19, aspergillus, aspergilosis pulmonar invasiva, síndrome de dificultad respiratoria del adulto.

\begin{abstract}
Abbreviations: Acute respiratory distress syndrome (ARDS); bronchoalveolar lavage fluid (BALF), continuous veno-venous hemodiafiltration (CVVHDF), coronavirus disease 2019 (COVID-19), COVID-19 associated pulmonary aspergillosis (CAPA), European Organization for Research and Treatment of Cancer/Mycosis Study Group (EORTC/MSG), galactomannan (GM), high-flow nasal cannula (HFNC), inhaled nitric oxide (iNO), intensive care unit (ICU), invasive fungal disease (IFD), invasive pulmonary aspergillosis (IPA), reverse transcriptase-polymerase chain reaction (rRT-PCR), tracheal aspirate (TA), prone positioning (PP), ventilator-associated pneumonia (VAP).
\end{abstract}

*alba.burgos.stm@gmail.com

ORCID: https://orcid.org/0000-0001-7403-1668 


\section{Introduction}

S ince December 2019, coronavirus disease 2019 (COVID-19) emerged from Wuhan City, China and rapidly spread to other countries becoming a pandemic threat[1]. Severe COVID-19 is characterized by acute respiratory distress syndrome (ARDS) secondary to viral pneumonitis that may require mechanical ventilation[2]. In our center we have encountered high number of COVID-19 patients developing invasive fungal disease (IFD), in particular invasive pulmonary aspergillosis (IPA). Aspergillus is one of the most common airborne saprophytic fungi. The spores are easily aerosolized, inhaled and normally eliminated in the immunocompetent host by innate immune mechanisms. In predisposed patients, Aspergillus can invade the bronchopulmonary system and cause invasive aspergillosis, being pulmonary aspergillosis the most frequent clinical manifestation of this entity[3].

More recently, retrospective case series from different countries[4]-[7] have reported evidence of COVID-19 associated pulmonary aspergillosis (CAPA) in a worrying $20 \%-35 \%$ of patients requiring mechanical ventilation[2].

Risk factors for IPA are well defined in immunocompromised population, like patients who experience prolonged neutropenia, haematopoietic stem cell transplant and solid organ transplant recipients[8],[9]. However, patients with ARDS due to viral infection are prone to secondary complications like IPA despite lack of prior underlying well-defined immunocompromising factors. ${ }^{7}$ Some studies explore the pathogenesis of IPA and host immune defects, showing that damage to the epithelium by influenza, defective fungal host responses in the lung and inflammatory conditions predispose to invasive aspergillo$\operatorname{sis}[2],[4],[9]-[11]$.

IFD during COVID-19 are still rarely reported and may be an important cause of morbidity and mortality. The frequency and impact of fungal co-infections has still been poorly studied and may be underdiagnosed. We retrospectively analysed patients with COVID-19 associated ARDS in the intensive care unit (ICU) who developed IPA at a single center.

\section{Matherial and Methods}

We performed a retrospective chart review of patients with COVID-19 and ARDS admitted to two of the five ICUs that were available at the Gregorio Marañon University General Hospital, Madrid. Inclusion criteria were: 1) patients admitted to ICU between March 16 $6^{\text {th }} ; 2020$ and April 16 $6^{\text {th }} ; 2020 ; 2$ ) positive reverse transcriptase-polymerase chain reaction ( $r R T-P C R$ nasopharyngeal-throat swab for COVID-19 and 3) diagnosis of IPA was performed combining clinical features, culture from respiratory samples and galactomannan (GM) detection.

According to the Berlin definition, ARDS was classified in 3 categories based on the severity of hypoxemia: mild $\left(\mathrm{PaO}_{2} / \mathrm{FiO}_{2}\right.$ of $200-300 \mathrm{mmHg})$, moderate $\left(\mathrm{PaO}_{2} / \mathrm{FiO}_{2}\right.$ of $\left.100-200 \mathrm{mmHg}\right)$, and severe $\left(\mathrm{PaO}_{2} / \mathrm{FiO}_{2} \leq 100 \mathrm{mmHg}\right)$, combined with criteria related to timing of the syndrome's onset, origin of edema, and the chest-X-ray findings[12].

rRT-PCR of nasopharyngeal swabs was performed to confirm the clinical diagnosis of COVID-19. Different types of tests were used depending on the availability of the center (ThermoFisher,
Vircell, Sansure, PMS International). IPA was suspected in those patients with poor clinical evolution. Platelia enzyme immunoassay (EIA) for GM (Bio-Rad Laboratories, CA) and quantitative determination of 1,3-beta-D-glucano in serum (Wako Pure Chemical Industries) was used. Also, bronchoalveolar lavage fluid (BALF) or tracheal aspirate (TA) culture and antifungal susceptibility testing were performed. In addition, a chest X-ray was performed every $48 \mathrm{~h}$.

Patients with COVID-19 diagnosis and under suspicious of Aspergillus infection were classified as putative, proven or colonized using Asp/CU algorithm[13]. The Asp/CU algorithm was developed for critically ill patients admitted to ICU and based on mycological criteria combining culture from respiratory specimens and galactomannan detection in the BALF and serum.

This study was carried out in accordance with the ethical principles reflected in the Declaration of Helsinki and was approved by the ethic committee of the Gregorio Marañon University General Hospital, Madrid, Spain.

\section{Results}

CAPA was found in 4 of 79 critically ill patients with severe ARDS admitted to two of the five ICUs available in our center (Table 1).

Patient \#1. A 52-years-old man with past history of obesity was admitted to our intensive care unit (ICU) because of ARDS due to COVID-19. Before ICU admission he received oxygen via nasal cannula and high-flow nasal cannula (HFNC). Eventually, he developed severe ARDS that require intubation and lung-protective mechanical ventilation. The chest $\mathrm{X}$-ray showed "crazy paving" pattern. The patient was treated with interferon $B$, tocilizumab, hydroxychloroquine, lopinavir/ritonavir and glucocorticoids. Prone positioning (PP) and inhaled nitric oxide (iNO) were applied with good results. A few days later worsening of respiratory insufficiency occurred. Serum GM and TA microbiological culture for Aspergillus terreus were positive. Intravenous voriconazole treatment was started but voriconazole levels could not be monitored in our center so antifungal therapy was change to isavuconazole. During his ICU stay he also developed pulmonary thromboembolism and ventilator-associated pneumonia (VAP) due to Enterococcus faecium. Finally, the patient died due to refractory hypoxemia.

Patient \#2. A 60-years-old woman presented with ARDS and COVID-19 diagnosis. She has past history of hypertension, asthma treated with inhaled corticosteroids and pre-dialysis chronic kidney disease. Endotracheal intubation, mechanical ventilation and PP were required due to severe hypoxemia. She was treated with tocilizumab, hydroxychloroquine, lopinavir/ritonavir and glucocorticoids. After 7 days of mechanical ventilation and good clinical outcome, extubation was carried out. However, 5 days later, she underwent endotracheal intubation again due to respiratory hypoxemic failure. Serum 1,3-beta-D-glucan and GM were positive. Aspergillus terreus grew in TA culture. Amphotericin $B$ was started. However, symptoms continue and antifungal agent was changed to isavuconazole and finally anidulafungin. She also developed VAP and acute renal failure requiring continuous veno-venous hemodiafiltration (CVVHDF). She died due to multiple organ dysfunction syndrome (MODS) and refractory hypoxemia. 
Table 1. Characteristics of patients admitted at ICU with COVID-19 and invasive pulmonary aspergillosis in our center

\begin{tabular}{|c|c|c|c|c|}
\hline & Patient - 1 & Patient - 2 & Patient - 3 & Patient - 4 \\
\hline Gender & Male & Female & Male & Male \\
\hline Age $(y)$ & 52 & 60 & 74 & 66 \\
\hline Arterial hypertension & No & Yes & Yes & No \\
\hline Dyslipidemia & No & No & Yes & Yes \\
\hline Diabetes mellitus & No & No & No & No \\
\hline Smoker & No & No & No & No \\
\hline Asthma/COPD & No & Yes & No & No \\
\hline $\begin{array}{l}\text { Underlying immuno- } \\
\text { compromising condition }\end{array}$ & No & $\begin{array}{l}\text { Inhaled corticosteroids } \\
\text { Pre-dialysis chronic kidney } \\
\text { disease }\end{array}$ & No & No \\
\hline BMI & 37.86 (obesity class 2) & 24.81 & 31.5 (obesity class 1 ) & - \\
\hline Treatment with ACEI/ARBs & No & No & Yes & No \\
\hline SOFA score & 4 & 7 & 5 & 7 \\
\hline Oxygenotherapy & $\begin{array}{c}\text { Oxygen nasal cannula } \\
\text { HFNC }\end{array}$ & Oxygen nasal cannula & Oxygen nasal cannula & Oxygen nasal cannula \\
\hline $\begin{array}{l}\text { Noninvasive mechanical } \\
\text { ventilation }\end{array}$ & No & $\begin{array}{l}\text { BiPAP previous } \\
\text { reintubation reintubación }\end{array}$ & CPAP $10 \mathrm{~cm} \mathrm{H}_{2} \mathrm{O}$ & No \\
\hline ARDS (PaFi)* & Severe & Severe & Severe & Severe \\
\hline - Intubation & Yes & Yes & Yes & Yes \\
\hline - Extubation & No & Yes & No & No \\
\hline - Reintubation & No & Yes & No & No \\
\hline - Prone positioning & Yes & Yes & Yes & Yes \\
\hline - iNO & Yes & No & No & No \\
\hline - vvECMO & No & No & No & No \\
\hline Venous thrombosis & Yes & No & No & No \\
\hline Acute renal faiure & No & Yes & Yes & No \\
\hline - CVVHDF & No & Yes & Yes & No \\
\hline \multicolumn{5}{|l|}{ Virology } \\
\hline - RT-PCR SARS-CoV-2 & $\begin{array}{l}\text { Nasopharyngeal-throat } \\
\text { swab }\end{array}$ & $\begin{array}{l}\text { Nasopharyngeal-throat } \\
\text { swab }\end{array}$ & $\begin{array}{l}\text { Nasopharyngeal-throat } \\
\text { swab }\end{array}$ & $\begin{array}{l}\text { Nasopharyngeal-throat } \\
\text { swab }\end{array}$ \\
\hline \multicolumn{5}{|l|}{ Microbiology } \\
\hline - Serum GM (> $0.5 \mathrm{ng} / \mathrm{ml})$ & Positive (1.94 ng/ml) & Positive $(0.58$ ng/ml) & Positive (1.94 ng/ml) & - \\
\hline Fungal culture & TA: Aspergillus terreus & $\begin{array}{c}\text { TA: Aspergillus fumigatus } \\
\text { y terreus }\end{array}$ & BALF Aspergillus lentulus & $\begin{array}{l}\text { BALF: Aspergillus } \\
\text { fumigatus }\end{array}$ \\
\hline AsplCU algorithm & Putative & Putative & Putative & Putative \\
\hline \multicolumn{5}{|l|}{ Therapy } \\
\hline - Antibiotherapy & Yes (ceftriaxone, 7 days) & Yes (cefuroxime, 6 days) & Yes (ceftriaxone, 4 days) & Yes (ceftriaxone, 4 days) \\
\hline - Antiviral therapy & $\begin{array}{c}\text { Yes (lopinavir/ritonavir, } 10 \\
\text { days) }\end{array}$ & Yes (10 days) & $\begin{array}{c}\text { Yes (lopinavir/ritonavir, } 10 \\
\text { days) }\end{array}$ & $\begin{array}{c}\text { Yes (lopinavir/ritonavir, } 10 \\
\text { days) }\end{array}$ \\
\hline - Glucocorticoids & $\begin{array}{l}\text { Yes (pulsed intravenous of } \\
\text { methylprednisolone) }\end{array}$ & $\begin{array}{l}\text { Yes (pulsed intravenous } \\
\text { methylprednisolone } \\
+ \text { non pulsed } \\
\text { methylprednisolone) }\end{array}$ & $\begin{array}{l}\text { Yes (non pulsed } \\
\text { methylprednisolone) }\end{array}$ & $\begin{array}{c}\text { Yes (dexamethasone+ } \\
\text { non pulsed } \\
\text { methylprednisolone) }\end{array}$ \\
\hline - Hydroxycloroquine & Yes (10 days) & Yes (10 days) & Yes (10 days) & Yes (10 days) \\
\hline - Interferon B & Yes & Yes & No & Yes \\
\hline - Tocilizumab & Yes (3 doses) & Yes (1 dose) & Yes (1 dose) & Yes (3 doses) \\
\hline - Remdesivir & No & No & Yes (5 days) & No \\
\hline
\end{tabular}




\begin{tabular}{|c|c|c|c|c|}
\hline - Azithromycin & No & No & No & No \\
\hline \multirow[t]{2}{*}{ Antifungal treatment } & Voriconazole (5 days) & Amphotericin B (16 days) & No & Voriconazole (24 h) \\
\hline & Isavuconazole (6 days) & $\begin{array}{c}\text { Anidulafungin }+ \\
\text { Isavuconazol (6 days) }\end{array}$ & & Isavuconazole (3 days) \\
\hline Other complications & $\begin{array}{l}\text { VAP (Enterococcus } \\
\text { faecium) }\end{array}$ & $\begin{array}{l}\text { VAP (Enterococcus } \\
\text { faecium) }\end{array}$ & $\begin{array}{l}\text { Reactivated CMV infection } \\
\text { Acute acalculous } \\
\text { cholecystitis with } \\
\text { secondary bacteremia due } \\
\text { to } E \text {. faecium } \\
\text { Acute hemorrhagic } \\
\text { pancreatitis }\end{array}$ & $\begin{array}{l}\text { VAP (Enterococcus } \\
\text { faecium) }\end{array}$ \\
\hline Outcome & $\begin{array}{c}\text { Died } \\
\text { Refractory hypoxemia }\end{array}$ & $\begin{array}{l}\text { Died } \\
\text { Refractory hipoxemia and } \\
\text { MODS }\end{array}$ & $\begin{array}{c}\text { Died } \\
\text { Acute hemorrhagic } \\
\text { pancreatitis }\end{array}$ & $\begin{array}{l}\text { Died } \\
\text { Refractory hipoxemia and } \\
\text { MODS }\end{array}$ \\
\hline
\end{tabular}

Abbreviations: ACEl: angiotensin converting enzyme inhibitors; ARBs: angiotensin receptor blockers; ARDS: Acute respiratory distress syndrome; BALF: Bronchoalveolar lavage fluid; BMl: body mass index; COPD: chronic obstructive pulmonary disease; CVVHDF: continuous veno-venous hemodiafiltration; GM: galactomannan; iNO: inhaled nitric oxide; HFNC: high-flow nasal cannula; MODS: Multiple Organ Dysfunction Syndrome; TA: tracheal aspirate; vvECMO: veno-venous extracorporeal membrane oxygenation; VAP: Ventilator-associated pneumonia; * Severity of ARDS was classified according Berlin definition in 3 categories (mild, moderate, and severe) based on the $\mathrm{PaO}_{2} / \mathrm{FiO}_{2}$ ratio. * Severity of ARDS was classified according Berlin definition in 3 categories (mild, moderate, and severe) based on the $\mathrm{PaO}_{2} / \mathrm{FiO}_{2}$ ratio.

Patient \#3. A 74-year-old man was transferred to the ICU due to ARDS and positive rRT-PCR for COVID-19. He has past history of hypertension and obesity. Treatment with oxygen nasal cannula and non-invasive mechanical ventilation failed, so endotracheal intubation was necessary. Treatment with azithromycin, interferon B, tocilizumab, hydroxychloroquine, lopinavir/ritonavir and glucocorticoids was started. Despite of mechanical ventilation and PP maneuvers he still presented refractory hypoxemia. Serum GM turned positive and AspergiIlus lentelus was isolated in bronchoalveolar lavage fluid (BALF) culture. During his stay in ICU he presented other complications: acute renal failure requiring $C V V H D F$, reactivated CMV infection, acute acalculous cholecystitis with secondary bacteremia due to Enterococcus faecium and acute hemorrhagic pancreatitis which causes his death. He did not receive antifungal treatment because of the late diagnosis of IPA.

Patient \#4. A 66-year-old-man with past history of dyslipidemia was admitted to the ICU because of ARDS due to COVID-19. Chest $X$-ray showed a non-homogeneously increased density, more remarkably in the bilateral lower zones and middle right zone. Mechanical ventilation and PP maneuvers were performed. He was treated with interferon $B$, tocilizumab, hydroxychloroquine, lopinavir/ritonavir and glucocorticoids. Refractory hypoxemia made necessary a prolonged intubation. Clinical worsening coincided with the isolated of Aspergillus fumigatus in BALF. Intravenous voriconazole treatment was started. However, therapeutic drug monitoring of voriconazole could not be performed in our center so the antifungal agent was changed to isavuconazole. During his ICU stay, the patient also developed VAP caused by Enterococcus faecium. The patient died due to refractory hypoxemia.

\section{Discussion}

IPA is a life-threatening disease generally occurring in immu- nocompromised patients[9],[11],[14]. Patients with ARDS due to viral infection are prone to IPA even in absence of prior host immune defects[7],[9],[11],[13]. We report 4 cases of patients with severe ARDS triggered by COVID-19 that developed IPA during their ICU stay.

Worsening of symptoms or radiographic pulmonary infiltrates in patients with COVID-19 are often attributed to progression of ARDS or bacterial superinfection, leading to an antimicrobial therapy without performing diagnostic procedures[2],[9].

Our case series suggest increased risk for critically ill COVID-19 patients to develop co-infection with Aspergillus despite the lack of prior immunosuppression. However, despite of the lack of prior underlying well-defined immunocompromising factors, most of the patients were treated with glucocorticoids, which are an important acquired immunological risk factor for IPA in patients with ARDS due to viral infection[15].

IPA needs to be considered in patients admitted to the ICU with COVID-19 and pulmonary infiltrates. These patients should be studied initially with noninvasive modalities such as serum biomarkers (GM and 1,3-beta-D-glucan), sputum and/ or TA fungal culture and chest computed tomography (CT). If the diagnosis is not made by these methods, a more invasive procedure may be necessary, like bronchoscopy to visualize the airways and obtain BALF for antigen testing and culture. $\mathrm{GM}$ is a universal polysaccharide component of the cell wall in Aspergillus species and is released into the BALF and blood during growth. The detection of the GM antigen in BALF and serum permit a reliable assay for the diagnosis of IPA, being GM in BALF more sensitive, with higher rate of false positive[16]

Also, chest CT in patients with suspicious IPA is strongly recommended[10],[15]. Meanwhile, CT scanning was deemed unfeasible in our center because of the situation of extreme hypoxia of some patients in addition to health system stress during these months. In our center the radiological monitoring was performed by chest X-ray every $48 \mathrm{~h}$.

The diagnosis of invasive aspergillosis is challenging owing 
to the lack of specificity of symptoms, the difficulty in discriminating between colonization and true infection, and the lower sensitivity of microbiological and radiological tests. According to the European Organization for Research and Treatment of Cancer/Mycosis Study Group (EORTC/MSG), a proven diagnosis requires tissue biopsy with histopathologic demonstration of tissue invasion by fungal hyphae. However, obtaining tissue specimens from critically ill patients is not always feasible[13]. The diagnosis is suspected in the presence of a combination of clinical, biological and radiologic findings on CT[9]. The Asp/CU algorithm is useful to discriminate Aspergillus respiratory tract colonization from IPA in critically ill patients with the absence of host factors[4],[13].

Treatment initiation depends on clinical judgement and risk assessment. It shouldn't wait for definitive diagnosis, which is often impossible in critically ill patients. First line treatment options for IPA include voriconazole and isavuconazole, being echinocandins and liposomal amphotericin B a good option in regions with high rates of azole-resistant[9]. Attaining the on-target serum antifungal level in ICU patients is challenging, in addition, inter and intraindividual variability has been observed in voriconazole plasma concentrations. Therapeutic drug monitoring (TDM) is useful to the effective use of voriconazole[17]. Serum levels of voriconazole could not be performed in our center. Also, the use of glucocorticoids like dexamethasone in treatment of patients with severe COVID-19 is being widespread. Some studies suggest the possibility that COVID-19 is in itself not a risk factor for IPA, but an association between corticosteroid usage and IPA is possible[2],[9].

This study has some limitations. Because of the pandemic and the overburdened health-care system, many doctors and nurses without experience in treatment of critically ill patients were recruited to provide care to patients with severe COVID-19. The lack of experience in this area combined with de challenging diagnosis of invasive aspergillosis may have delayed the treatment of these patients. In respect of diagnosis tools, BALF GM antigen detection has a higher efficiency than serum GM detection for the diagnosis of IPA[18] as well as chest CT is preferred in these patients[10],[15]. However, in our center serum GM antigen was carried out and radiological monitoring was performed by chest $\mathrm{X}$-ray.

\section{Conclusion}

COVID-19 has emerged as a new viral infection all around the globe. In spite of the lack of underlying immunosuppression, patients with COVID-19 seem to be at risk of developing IPA. IPA may complicate severe COVID-19 pneumonia, leading to enhanced illness severity and mortality.

Although the diagnosis of IPA in the ICU is challenging, due to the difficulty of differentiate between infection and colonization, and the non-specificity of radiological images, it should be considered in patients admitted to the ICU with COVID-19.

With this article we want to give a warning of the presence of Aspergillus infection in COVID-19 patients and keep it in mind when there is a clinical worsening. Early diagnosis and treatment of Aspergillus is mandatory in order to avoid its potential detrimental outcome. More studies are necessary to investigate fungal co-infections in patients with COVID-19 disease.

\section{References}

1. Guan W-J, Ni Z-Y, Hu Y, Liang W-H, Ou C-Q, He J-X, et al. Clinical Characteristics of Coronavirus Disease 2019 in China. N Engl J Med. 30 de 2020;382(18):1708-20.

2. Armstrong-James D, Youngs J, Bicanic T, Abdolrasouli A, Denning DW, Johnson E, et al. Confronting and mitigating the risk of COVID-19 associated pulmonary aspergillosis. Eur Respir J. 2020;56(4)

3. Shah MM, Hsiao El, Kirsch CM, Gohil A, Narasimhan S, Stevens DA. Invasive pulmonary aspergillosis and influenza co-infection in immunocompetent hosts: case reports and review of the literature. Diagn Microbiol Infect Dis. junio de 2018;91(2):147-52.

4. Rutsaert L, Steinfort N, Van Hunsel T, Bomans P, Naesens R, Mertes $\mathrm{H}$, et al. COVID-19-associated invasive pulmonary aspergillosis. Ann Intensive Care. 1 de junio de 2020;10(1):71.

5. Alanio A, Dellière $S$, Fodil $S$, Bretagne $S$, Mégarbane B. Prevalence of putative invasive pulmonary aspergillosis in critically ill patients with COVID-19. Lancet Respir Med [Internet]. 20 de mayo de 2020 [citado 1 de noviembre de 2020]; Disponible en: https:// www.ncbi.nlm.nih.gov/pmc/articles/PMC 7239617/

6. van Arkel ALE, Rijpstra TA, Belderbos HNA, van Wijngaarden P, Verweij PE, Bentvelsen RG. COVID-19-associated Pulmonary Aspergillosis. Am J Respir Crit Care Med. 01 de 2020;202(1):1325.

7. Koehler P, Cornely OA, Böttiger BW, Dusse F, Eichenauer DA, Fuchs $F$, et al. COVID-19 associated pulmonary aspergillosis. Mycoses. junio de 2020;63(6):528-34.

8. Blanchard E, Gabriel F, Jeanne-Leroyer C, Servant V, Dumas P-Y. [Invasive pulmonary aspergillosis]. Rev Mal Respir. febrero de 2018;35(2):171-87.

9. Verweij PE, Rijnders BJA, Brüggemann RJM, Azoulay E, Bassetti $M$, Blot $S$, et al. Review of influenza-associated pulmonary aspergillosis in ICU patients and proposal for a case definition: an expert opinion. Intensive Care Med. 22 de junio de 2020;1-12.

10. Koehler P, Bassetti M, Kochanek M, Shimabukuro-Vornhagen $A$, Cornely OA. Intensive care management of influenza-associated pulmonary aspergillosis. Clin Microbiol Infect Off Publ Eur Soc Clin Microbiol Infect Dis. diciembre de 2019;25(12):1501-9.

11. Schauwvlieghe AFAD, Rijnders BJA, Philips N, Verwijs R, Vanderbeke L, Van Tienen $C$, et al. Invasive aspergillosis in patients admitted to the intensive care unit with severe influenza: a retrospective cohort study. Lancet Respir Med. 2018;6(10):782-92.

12. Fan E, Brodie D, Slutsky AS. Acute Respiratory Distress Syndrome: Advances in Diagnosis and Treatment. JAMA. 20 de febrero de 2018;319(7):698-710.

13. Blot SI, Taccone FS, Van den Abeele A-M, Bulpa P, Meersseman W, Brusselaers $\mathrm{N}$, et al. A clinical algorithm to diagnose invasive pulmonary aspergillosis in critically ill patients. Am J Respir Crit Care Med. 1 de julio de 2012;186(1):56-64.

14. Sarwar M, Gardezi SAH, Zaman G, Ikram A, Satti L, Khadim MT. Evaluation of galactomannan and beta-d-glucan assays for the diagnosis of invasive aspergillosis in clinically suspected cases. JPMA J Pak Med Assoc. marzo de 2020;70(3):442-6.

15. Donnelly JP, Chen SC, Kauffman CA, Steinbach WJ, Baddley JW, Verweij PE, et al. Revision and Update of the Consensus Definitions of Invasive Fungal Disease From the European Organization for Research and Treatment of Cancer and the Mycoses Study Group Education and Research Consortium. Clin Infect Dis Off Publ Infect Dis Soc Am. 5 de diciembre de 2019;71(6):1367-76. 


\section{Artículo Original}

16. Zhang S, Wang S, Wan Z, Li R, Yu J. The Diagnosis of Invasive and Noninvasive Pulmonary Aspergillosis by Serum and Bronchoalveolar Lavage Fluid Galactomannan Assay. BioMed Res Int [Internet]. 2015 [citado 25 de noviembre de 2020];2015. Disponible en: https://www.ncbi.nlm.nih.gov/pmc/articles/PMC4317593/

17. Cabral-Galeano E, Ruiz-Camps I, Len-Abad O, Pou-Clavé L, Sordé-Masip R, Meije-Castillo Y, et al. Clinical usefulness of ther- apeutic drug monitoring of voriconazole in a university hospital. Enferm Infecc Microbiol Clin. mayo de 2015;33(5):298-302.

18. Zhou W, Li H, Zhang Y, Huang M, He Q, Li P, et al. Diagnostic Value of Galactomannan Antigen Test in Serum and Bronchoalveolar Lavage Fluid Samples from Patients with Nonneutropenic Invasive Pulmonary Aspergillosis. J Clin Microbiol. julio de 2017;55(7):2153-61. 